\title{
Unusual presentation of adrenal lymphoma observed with PET-CT
}

\author{
Adrenal lenfomanin PET-BT'deki ilginç görünümü
}

\author{
Zeynep Gözde Özkan ${ }^{1}$, Cüneyt Türkmen ${ }^{1}$, Yasemin Şanlı1 ${ }^{1}$, Mustafa Nuri Yenerel${ }^{2}$, \\ Issik Adalet ${ }^{1}$ \\ 'Department of Nuclear Medicine, İstanbul Medical Faculty, İstanbul University, İstanbul, Turkey \\ ${ }^{2}$ Department of Hematology, Istanbul Medical Faculty, Istanbul University, Istanbul, Turkey
}

\section{To the Editor,}

Lymphoma presenting with enlarged adrenal glands is not common. According to the literature, most adrenal lymphomas do not have extra-adrenal sites. We examined a 47-year-old male patient because of abdominal pain-an unusual presentation of adrenal lymphoma. Following ultrasonographic examination that showed bilateral massively enlarged adrenal glands, the patient underwent F-18 FDG PETCT. Written informed consent was obtained from the patient prior to PET-CT examination.

PET-CT showed bilateral enlarged adrenal glands (right: $67 \times 55 \mathrm{~mm}$; left: $28 \times 68 \mathrm{~mm}$ ) and increased FDG uptake (SUVmax: 27-25) (Figure 1a). Additional foci of increased FDG accumulations were observed, as follows: in the millimetric parenchymal nodule on the middle lobe and in the parenchyma (with groundglass density) on the lower lobe of the right lung (Figure 1b); in pleural surfaces on the right hemithorax (Figure 1c); in peripancreatic and para-aortic lymph nodes in the abdomen-the largest of which was $3 \mathrm{~cm}$ in diameter (Figure 1d); in the right caput humeri and in the corpus of 4 . lumbar vertebra
(Figure 1e). All of these uptakes were in the range of malignant disease. CT-guided biopsy of the right adrenal gland showed diffuse large B cell lymphoma, which is the most common type of adrenal lymphoma.

Most patients with adrenal lymphoma present with bilateral enlarged adrenal masses, without evidence of extra-adrenal spread [1,2]. Although some patients have extra-adrenal involvement [3-5], the presented patient had highly disseminated disease. The presence of multiple extranodal sites in lymphoma patients at presentation is associated with poor prognosis [4]. Generally, the response to chemotherapy is not good in such patients [5]. After the presented patient completed 3 cycles of R-CHOP chemotherapy, PET-CT showed that all previous hypermetabolic foci were normalized (Figure 2a-c) and that there were new foci of uptake in the interhemispheric area, in the frontal and right temporal lobes of the cerebrum (Figure 2d), in various vertebral bodies (Figure 2e), and in the intramedullary space between 1. and 2 lumbar vertebrae (Figure 2f).

Patients with adrenal lymphoma have a tendency for late central nervous system involvement, as the 


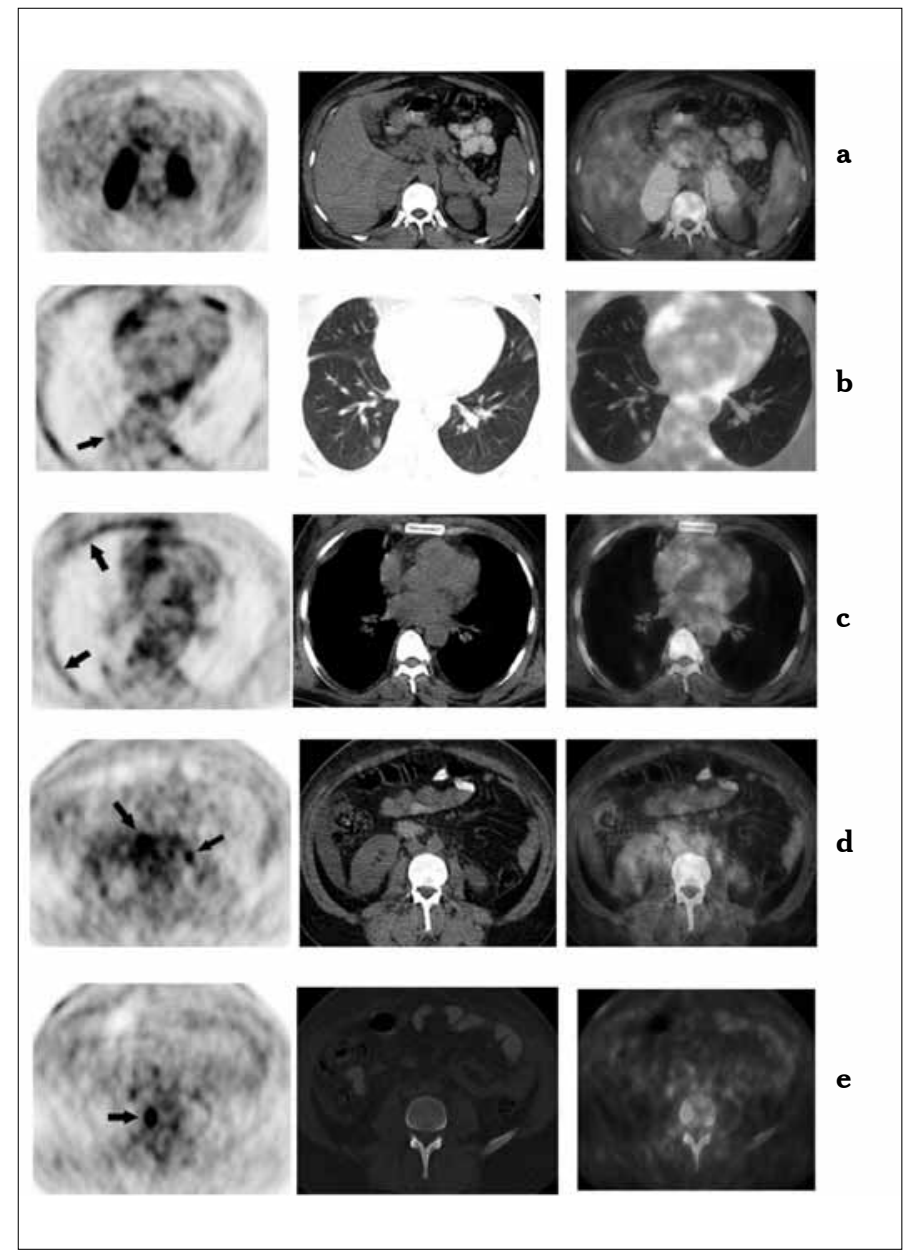

Figure 1. PET-CT Which Was Taken During the Evaluation Process of Bilateral Enlarged Adrenal Glands of the Patient

presented patient did [2]. Despite all treatment efforts, patients usually die within 1 year [5]. After follow-up PET-CT the presented patient was scheduled to continue receiving chemotherapy; however, pulmonary Pneumocystis jiroveci infection was subsequently diagnosed and following antibiotic therapy the patient died due to fungal superinfection without having received additional chemotherapy.

The presented patient had an unusual presentation of adrenal lymphoma with multiple, extra-adrenal involvement at the time of diagnosis and expected onset of the disease. The patient developed new sites of disease, including the central nervous system, while undergoing chemotherapy and died after 6 months from the diagnosis of his disease.

\section{Conflict of interest statement}

The authors of this paper have no conflicts of interest, including specific financial interests, relation-

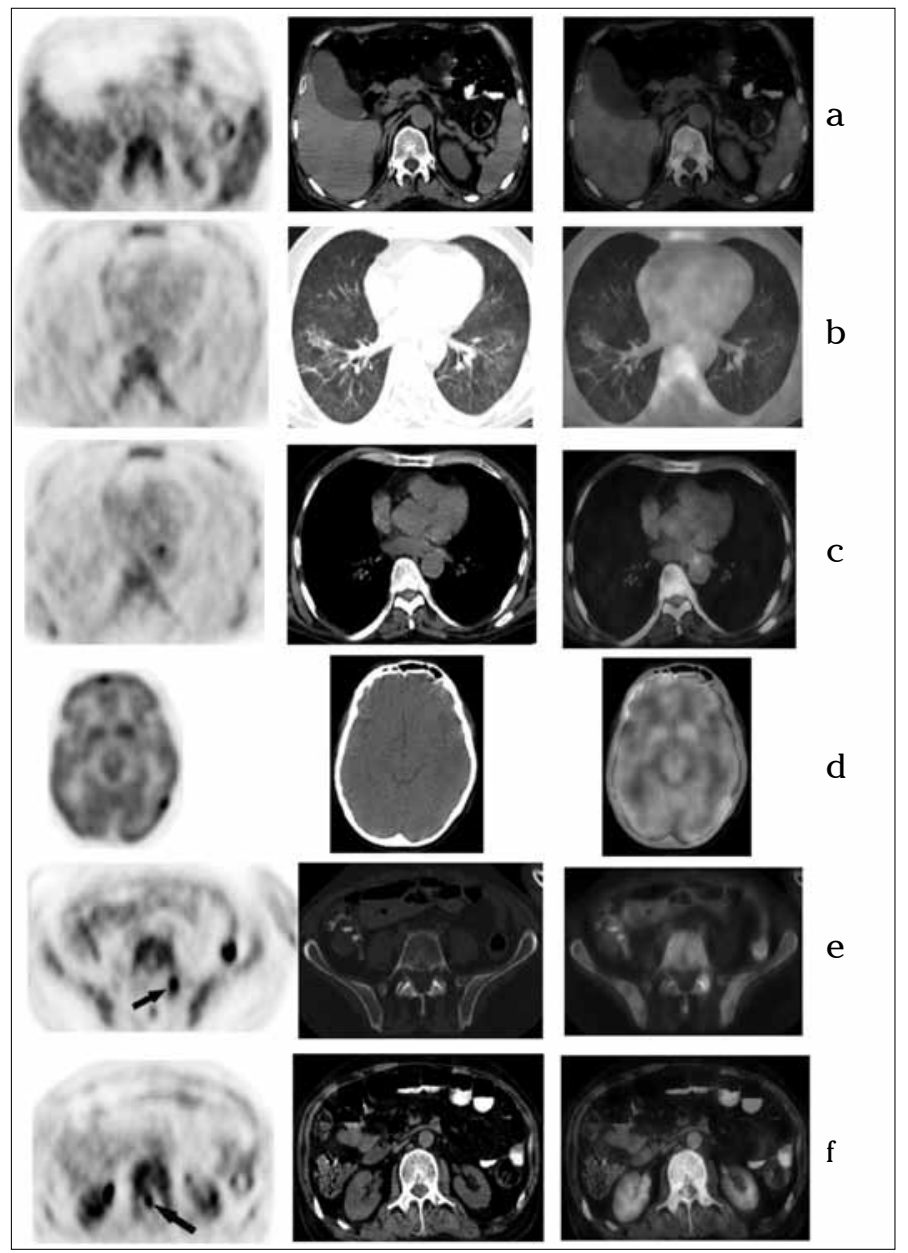

Figure 2. PET-CT of the Patient After 3 Cycles of R-CHOP Chemotherapy

ships, and/or affiliations relevant to the subject matter or materials included.

\section{References}

1. Kumar R, Xiu Y, Mavi A, El-Haddad G, Zhuang H, Alavi A. FDG-PET imaging in primary bilateral adrenal lymhoma:A case report and review of the literature. Clin Nucl Med 2005;30:222-30. [CrossRef]

2. Wang J, Sun H, Bai R, Gao S, Li Y. 18F-FDG PET/CT images in primary adrenal lymphoma. European Journal of Radiology Extra 2008;68:83-7. [CrossRef]

3. Brink I, Schneider B, Hoegerle S. Enormous bilateral adrenal uptake of F-18 FDG caused by non-Hodgkin's lymphoma. Clin Nucl Med 2002;27:739-40. [CrossRef]

4. Singh D, Sharma A, Mohanti BK, Thulkar S, Bahadur S, Sharma SC, Gupta SD. Multiple extranodal sites at presentation in non-Hodgkin's lymphoma. Am J Hematol 2003;74:75-7. [CrossRef]

5. Barbaros U, Erbil Y, Bozbora A, Deveci U, Özarmağan S, Kapran Y. Primary adrenal lymphoma presenting as bilateral adrenal masses. The Endocrinologist 2006;16:75-6. [CrossRef] 